\title{
A Review of the Modern Higher Foreign Language Education in Sichuan from Sichuan Chinese and Western School
}

\author{
Luhua Gan ${ }^{1, *}$ \\ ${ }^{1}$ Sichuan University, Chengdu, Sichuan 610064, China \\ *Corresponding author. Email: $8534301 @$ qq.com
}

\begin{abstract}
Taking Sichuan Chinese and Western School as an example, this paper discusses the development of higher foreign language education in modern Sichuan. Through the verification of historical documents, the paper analyzes the background and influence of the establishment of the Sichuan Chinese and Western School, and points out its role in promoting the development of foreign language education in Sichuan. Sichuan Chinese and Western School is the origin of modern higher education in Sichuan. With English and French as the major courses, the school was a pioneer in Sichuan higher foreign language education in modern times, from the introduction of foreign language learning to the absorption of western advanced sciences and technologies and from the purpose of running schools to teaching methods. The establishment of Sichuan Chinese and Western School was a sign of the modernization of higher education in Sichuan, and this process began with foreign language education, in which foreign language education also went ahead of the modernization of other disciplines.
\end{abstract}

Keywords: Sichuan Chinese and Western School, Foreign language education, Sichuan University.

\section{INTRODUCTION}

In 1896, Lu Chuanlin, the governor of Sichuan and the grand coordinators of Guangdong, a westernization movement, founded the Sichuan Chinese and Western School, which was characterized by the learning of "Western culture and Western skills". It is the predecessor of the present Sichuan University and the beginning of modern higher education in Sichuan province. With English and French as major courses, the school was a pioneer in Sichuan higher foreign language education in modern times, from the introduction of foreign language learning to the absorption of western advanced sciences and technologies and from the purpose of running schools to teaching methods. The establishment of Sichuan Chinese and Western School marked the modernization of higher education in Sichuan, and this process began with foreign language education, in which foreign language education also went ahead of the modernization of other disciplines.

\section{THE ESTABLISHMENT OF SICHUAN CHINESE AND WESTERN SCHOOL AND ITS INFLUENCE ON HIGHER FOREIGN LANGUAGE EDUCATION IN SICHUAN}

At the end of the 19th century, in order to save the country from crisis, the Qing Government issued the imperial edict to abolish the shuyuan (academy of classical learning in ancient China) and set up universities, and various localities set up new universities at all levels. As a senior representative of Westernization Group, $\mathrm{Lu}$ Chuanlin was well aware of the significance of pursuing education for his country and nation. At the beginning of the establishment of the school, he wrote in his memorial to the Qing Court:

The emphasis on western learning and the establishment of universities are actually the basis for today's efforts to build a prosperous and strong country. Located far in the southwest, the thoughts 
of people in Sichuan province are limited to what they see and hear, so it is especially appropriate to encourage learning there so as to create a new atmosphere. In my previous memorial to discuss and reply the current affairs, all these are clarified. Then I invited the Ministry of Foreign Affairs to send two persons well versed in English and French respectively, to Sichuan as teachers. I also consulted the books needed for running a school from arriving, sent personnel to Shanghai to purchase foreign books for study, searched for and purchased the site in person for the construction of school buildings. The hardest part falls on raising funds. Local magistracy is ordered to assign fifty thousand ounces of silver that can be raised and delivered to the Salt Bureau for interests as the founding funds. The English deputy teacher Changde and French deputy teacher Enxi selected from Beijing have been brought with the foreign books to Sichuan. And the books distributed by the north and south foreign trade minister as well as those bought are also arriving. The last concern is the construction of the school buildings requires about 8 months before completion. ${ }^{1}$ [1]

It can be seen from the memorial that the establishment of the Chinese and Western School lies in the learning of Western languages and Western skills, and it is an important measure to invite the six teachers of English and French who are familiar with English and French literature to Sichuan in building this school. Later, in his instructions to the notification by Sichuan Westernization General Administration, Lu Chuanlin pointed out more clearly that:

The teaching goal of the school should be making students able to translate both English and French to Chines and be proficient in Chinese and Western math, and in several years, forming their aspiration, adopting strict evaluation for their awe of study, incentivizing them with generous awards, so as to make them stimulated and hone themselves. In some years, the results can be yielded gradually, which will also benefit the time. ... Since the trend has not been formed in Sichuan, it is especially necessary to advocate new education as the starting point, in order to cultivate more talents. Therefore, it is necessary to build schools, hire teachers, and

1. Memorial of Lu Chuanlin, Governor of Sichuan. "Another Statement on the Issue of Setting up a Western School in Sichuan". Archives of Sichuan Chinese and Western School, Vol. 1. widely select juniors to learn western languages as well as Chinese. ${ }^{2}[4]$

As a representative of Westernization Group who had opened his eyes to the world at that time, $\mathrm{Lu}$ Chuanlin was well aware that the first thing for enriching the country and increasing its military force was to "establish schools and focus on current affairs" and that "with so many negotiations between China and foreign countries, prosperity can never be reached without talents that are well informed of the trend of the times". ${ }^{3}$ [4] In order to cultivate the talents well informed of the trend of the times, it is necessary to lay stress on current affairs and promote new learning. However, the new learning based on "Western language and Western skills" must be based on "Western language". Without the help of language tools, it is impossible to learn western science and culture. Therefore, the establishment of modern higher foreign language education is bound to be an important work at the beginning of modern higher education, and the Sichuan Chinese and Western School which completed this work initiated the forerunner of higher foreign language education in modern Sichuan.

The courses of the Sichuan Chinese and Western School advocated "departmental teaching". At the beginning, English and French subjects mainly took their own language and literature courses, including phonetic, spelling, intensive reading, translation and other professional courses. After the establishment of the school of mathematics, the three subjects were put together according to the instructions of the governor of Sichuan province, and foreign language and Sinology became compulsory basic courses for students. The school executed "hierarchical teaching". The youths normally had prior courses first (be equivalent to preparatory course), then a year later, got to the inside hall as "students" and finished school after the third year. ${ }^{4}$ [1] Among them, the strong performers can get to the "inside hall" earlier as "seniors", and also graduate at the end of the third year. As for the evaluation of

2. Memorial of Lu Chuanlin. "Imperial Archives of Guangxu Dynasty", compiled by Taipei's National Palace Museum. Quoted in "Memory of Sichuan University: Lu Chuanlin and Sichuan University", p. 29.

3. Memorial of Lu Chuanlin. "Imperial Archives of Guangxu Dynasty", compiled by Taipei's National Palace Museum. Quoted in "Memory of Sichuan University: Lu Chuanlin and Sichuan University", p. 30.

4. Source: Archives of Sichuan Chinese and Western School, Vol. 5 
"students", "the addiction of English and French spelling, mathematics and geography and introduction in a timely manner, so as to make them grasp the knowledge" are adopted." Yet those who have not been clear about Chinese and have a hard time in learning the Western languages, could only make more efforts in their prior courses. It can be seen that foreign language proficiency has always been an important subject in students' exam upgrading, and foreign language education is particularly prominent in the teaching arrangement of Sichuan Chinese and Western School.

As the first provincial-level new-style school at that time, the school was strongly supported by $\mathrm{Lu}$ Chuanlin, governor of Sichuan province, from the very beginning. He used the local land tax to buy land for school buildings, hire foreign teachers, add equipment and buy books. At that time, the school library bought back all the original English and French books and periodicals and related books and periodicals published in China they can. According to statistics in 1902, in the collection of more than 10000 books, in addition to a large number of British and French dictionaries, grammar books, history and policy books, Oxford dictionaries, French grammar, French historical records, and the map of all the nations etc., there were more English, French geography books, physics books, machine books, geometry books, mathematics books and other western natural science books and educational books. At the same time, the library also contained the original versions of the enlightened reading materials promoting the western bourgeois revolution and the Chinese translations of Yan Fu, Lin Shu and others. "Evolution and Ethics and other Essays", "The Wealth of Nations", "De l'esprit des lois (the Spirit of Law)" and "Confessions" and other books were on the list. Its variety, quantity and category, was second to none at that time in Sichuan. This not only supported the teaching needs of schools, but also spread western cultural knowledge to a certain extent, injecting fresh air into the closed Sichuan.

\section{THE HISTORICAL BACKGROUND OF THE SCHOOL AND ITS INFLUENCE}

People will have a deeper understanding of this period of history by further studying the establishment and development of Sichuan Chinese and Western School in the turbulent historical background at that time. After the Xin You Coups in 1861 , in order to save the ruling crisis of, some members of the Qing Government, such as Zeng Guofan, Li Hongzhang, Zuo Zongtang and Zhang Zhidong, advocated the introduction and imitation of Western weapons and equipment, the study of Western science and technology, the establishment of modern enterprises and the establishment of new schools, thus the westernization movement was launched. In July 1862, Prince Kung Yixin, Li Hongzhang and Zeng Guofan were permitted to set up the School of Combined Learning in Beijing, attached to the Ministry of Foreign Affairs. It was a "Westernization School" for the training of translators, having classes only in English, French and Russian. With the deepening of westernization movement, many translators were sent to various government offices after graduation from the School of Combined Learning. They only knew "Western language", but did not know what the "Western skills", such as mathematics, metaphysics, machinery and navigation, were, so they were not competent to deal with foreign affairs. To solve this problem, it was necessary to adjust the curriculum of foreign language schools. In many foreign language schools, the cultivating mode of mastering "Western skills" through "Western languages", and some attention was also paid to the training of speaking and listening. At the same time, on the basis of "Western languages", the subjects of "Western skills" were added, and the length of schooling was extended accordingly. In 1867, the School of Astronomy and Mathematics of the School of Combined Learning began to recruit students. The courses increased year by year, and many subjects of natural science and practical technology were introduced. Some courses were also divided in a subdivided and professional way. For example, mathematics is divided into mathematical enlightenment, algebra, geometry, flat triangle, arc triangle, and calculus and so on. The length of schooling has been adjusted from 3 years to 8 years, and many courses on "Western skills" have been added. Foreign language is still the main course. The eight-year curriculum of the School is shown in "Table 1" as follows:

The curriculum reflects the school's emphasis on translation. The principle of gradual and orderly progress is observed in teaching, which aims to help students to learn foreign languages and then be engaged in other subjects, mainly including the practical science of mathematics, which reflects the school-running mode of seeking "Western skills" through "Western languages". At this point, the School of Combined Learning realized the transformation from a comprehensive school based 
on foreign languages and taking other subjects into consideration. In 1902, it was incorporated into the Imperial University of Peking and further developed into the predecessor of the Department of Foreign Languages and Literatures, Tsinghua University. The School of Combined Learning was the first westernization school in Beijing in the
Qing Dynasty to adopt the class teaching system. After the School of Combined Learning in Beijing, the Westernization Group built two such schools in Shanghai and Guangzhou, which contributed to the spread of Western scientific and cultural knowledge and the cultivation of new talents. [7]

Table 1. The eight-year curriculum of the School of Combined Learning

\begin{tabular}{|l|l|l|l|}
\hline \multicolumn{1}{|c|}{ Year } & \multicolumn{1}{|c|}{ Learning content } & \multicolumn{1}{|c|}{ Year } & \multicolumn{1}{|c|}{ Learning content } \\
\hline 1st year & Reading and writing; learning of simple expressions & 2nd year & $\begin{array}{l}\text { Interpretation of the simple books; } \\
\text { practicing grammar; notes translation }\end{array}$ \\
\hline 3rd year & $\begin{array}{l}\text { Explaining the maps of countries; reading the histories of 4th year } \\
\text { different countries; selected works translation }\end{array}$ & $\begin{array}{l}\text { Mathematical enlightenment; algebra; } \\
\text { documents translation }\end{array}$ \\
\hline 5th year & $\begin{array}{l}\text { Investigation and research; Elements of Geometry; flat6th year } \\
\text { triangle; arc triangle and practicing translation press }\end{array}$ & $\begin{array}{l}\text { Learning machines; differential integral; } \\
\text { nautical to measure; practice of book } \\
\text { translation }\end{array}$ \\
\hline 7th year & $\begin{array}{l}\text { Learning chemistry; astronomical calculation; public law of 8th year } \\
\text { nations; practice of book translation }\end{array}$ & $\begin{array}{l}\text { Astronomical calculation; geography: } \\
\text { metal and stone; Manual of Political } \\
\text { Economy; practice of book translation }\end{array}$ \\
\hline
\end{tabular}
Wei. An Exploratory Study of English Teaching Localization in China and School of Combined Learning. Social Sciences in Guangxi, 10 th issue of 2006.

Table 2. The curriculum schedule of Chinese and Western School

\begin{tabular}{|c|c|c|}
\hline Subjects & Curriculum & Credit \\
\hline Foreign languages & Phonics, spelling, grammar, intensive reading, translation & \\
\hline \multicolumn{3}{|c|}{ National culture quintessence } \\
\hline Mathematics & Mathematical enlightenment & 6 \\
\hline Geometry & Fractals, Elements of Geometry & 16 \\
\hline Algebra of equation & Algebra & 12 \\
\hline Congruent triangle & $\begin{array}{l}\text { Main points of flat triangle, essence of mathematics, main points of arc } \\
\text { triangle, "Li Xiang Kao Cheng" (a work on calendar calculation) }\end{array}$ & 40 \\
\hline Parallel dynamics & Pictorial handbook of dynamics & 7 \\
\hline Higher algebra & $\begin{array}{l}\text { Algebra, Analytic Geometry, theory of curve, Elements of Analytical } \\
\text { Geometry, and of the Differential and Integral Calculus, algebraic } \\
\text { problems, micro product traceability, fractional calculus tracing, the theory } \\
\text { of curve }\end{array}$ & 163 \\
\hline Advanced trigonometry & Trigonometric mathematics, study of making lines & 48 \\
\hline Higher dynamics & Dynamics & 30 \\
\hline Geodesy & Geodesic drawing, marching drawing, drawing method & 48 \\
\hline Astrometry & $\begin{array}{l}\text { Li Xiang Kao Cheng, study of the five elements of heaven and earth, } \\
\text { astronomy synopsis, nautics, Usage of Qie Bai Si Tian Astrometry Table }\end{array}$ & 110 \\
\hline
\end{tabular}

By contrast, it is not difficult to find that the Sichuan Western and Chinese School in are similar to them in many aspects, such as the establishment goal, school system, curriculum setting, development track, etc. For example, they are all westernization schools taught in class; at the beginning, they mainly taught foreign languages, and then they successively added mathematics and other subjects. In 1902, the School of Combined Learning was incorporated into the Imperial
University of Peking and renamed as Translational School, becoming the predecessor of the School of Foreign Languages of Peking University. And Sichuan Chinese and Western School became the predecessor of Sichuan University and the origin of higher foreign language education in Sichuan. By the time Lu Chuanlin founded Sichuan Chinese and Western School in 1898, foreign language schools such as the School of Combined Learning had gradually completed the transformation from a 
specialized language school to a comprehensive teaching institution focusing on foreign languages. Sichuan Chinese and Western School, on the other hand, drew on the advanced experience of the schools of combined learning in different places, especially the School of Combined Learning in Beijing, and at the same time, it took in the idea of running a comprehensive new school of higher learning at that time. It was new higher school based on the study of "Western languages and Western skills", as well as new technologies such as mathematics and geography. In Sichuan Chinese and Western school, the measure to fully embody this idea is to set up the school of mathematics. In 1899, the General Administration of Westernization Affairs of Sichuan confirmed in document that "In Western studies, no matter it is natural sciences or measurement, mathematics is the threshold" and that "Mathematics is the source of surveying and mapping and the step for prosperity and prosperity to use", and added mathematics as a discipline. Kui Jun, then governor of Sichuan province, also made clear instructions in the document of Sichuan Westernization General Administration: "The establishment of the school is not only to understand the languages, but also to instruct the students in the study of astronomy, geography, measurement, and the history of different countries, from the simple to the profound, gradually inducing them to keep improving." 5 Since the establishment of the School, Sichuan Chinese and Western School has added 26 specialized courses in 10 categories in addition to the basic courses of foreign languages and Sinology, making it a comprehensive new school with foreign language education as its basis and covering multiple disciplines. This can be seen from the curriculum schedule of Chinese and Western School in "Table 2" above. ${ }^{6}$ [1]

From the establishment of the school when only the majors of English and French were set up at the beginning, to the establishment of the school of mathematics, Sichuan Chinese and Western School also had the experience of beginning with Western languages, and seeking Western skills through Western language, and finally being transformed into a comprehensive modern higher education. Such a development pattern was common at the beginning of the establishment of many modern universities. It reflects from one side that language, as a tool for learning and studying other cultures, is

5. Source: Archives of Sichuan Chinese and Western School, Volume 1

6. Source: Archives of Sichuan Chinese and Western School, Volume 1 at least an important tool when conducting cultural exchanges, actively or passively. Therefore, in the late Qing Dynasty, people like Lu Chuanlin, who realized this problem, started with foreign language education and gradually introduced the comprehensive study of various advanced western cultures — "With the current convenience in traffic, travelling to Europe and America is just like dropping around within a community; being unable to read and communicate in their languages means being not able to know things about them." 7 [6] "In today's world, we have to pay attention to western learnings; with more and more negotiations between China and the West going on day by day, how can we deal with them safely if we don't understand the Western languages?" 8 The "Outline of Academic Affairs" issued in 1903 stated, "In today's world, people who do not have access to the foreign languages are in a great obstacle in dealing with foreign affairs, traveling and studying abroad." 9 [5] In the late Qing Dynasty, although selfimprovement and even survival were the realistic historical priorities, the intense cultural conflicts between the East and the West were the essential matter. The key to turning passivity into initiative in this conflict is the attitude towards foreign cultures. The establishment of higher foreign language education could not only show the attitude of those in power, but also cultivate talents and provide tools to further understand and learn Western culture. Therefore, with the rise of foreign language education, it was inevitable to have a comprehensive study of Western culture, such as science and technology and management, and urgently apply the results of this study and trained talents to the reality of China's national salvation. Qian Weishan, one of the first graduates of Sichuan Chinese and Western School majoring in English, studied electrical and mechanical engineering at Birkbeck College, University Of London. After returning home, he served as the director of Sichuan Telephone Bureau and then as the President of Sichuan Industrial School (the predecessor of Engineering School of Public Sichuan University). Hu Xiang, a graduate majoring in French, studied in Paris University, France, and after he returned to China, he was appointed as the officer of the National Academy

7. Zhu Youhuan. Historical Materials of Modern Chinese Academic System. Shanghai: East China Normal University Press, 1987, P358. (in Chinese)

8. "Chinese Need to Master Western Language". Shendaily, 1895-10-30. (in Chinese)

9. Shu Xincheng. Data on the History of Chinese Modern Education. Beijing: People's Education Press, 1961. 
and then served as the director of Sichuan Machinery Bureau. $\mathrm{He} \mathrm{Lu}$, a graduate majoring in mathematics, studied in Tokyo Advanced Industrial School, Japan. After returning to China, he taught in a new school. He was one of the most famous mathematicians and physicists in Sichuan in modern times.

After the Opium War, some Chinese people of insight were shocked by the ships and armament of the West, and they felt the lack of talents and the weakness of national strength. In the process of dealing with foreigners, resisting foreign aggression, and contacting with foreign cultures, this part of the Chinese gradually realized that the Western ships and guns were far superior to those of China, and that the modern sciences of foreigners were indeed useful. Thus, the idea of "learning the skills of foreigners to defeat foreigners" came into being spontaneously. But to learn from and to defeat them, the first thing was do should be to know about them. To know about foreigners, it is the prerequisite for cultural exchange to know foreign languages and understand foreign customs and other facts about them. Therefore, it was urgent to cultivate new talents who can speak foreign languages and know foreign advanced technologies. Therefore, it was very realistic to open new schools focusing on Western languages and Western skills, which objectively promoted the development of foreign language learning. As a means of knowing foreigners, the aim of learning foreign languages is to learning from the "skills" of them. With the rapid development of China's modernization process, the "skills" mentioned then has developed rapidly from the initial strong ships and guns and modern technologies to transportation, postal service, diplomacy and management and other aspects of modern social life. Yet as a carrier of technology, talent training was far from meeting the urgent needs of social development at that time. Therefore, in the late Qing Dynasty and early Republic of China, China's internal and foreign affairs were controlled by foreigners in many aspects. On the one hand, it was caused by the weakness of the government as well as the lagging talent cultivation. Taking transportation as an example, "As far as modern China is concerned, there were really not many excelling in railway construction; the builder of Beijing-Zhangjiakou Railway $\mathrm{Mr}$. Zhan and that of Canton-Hankow railway Mr. Wang were well-renowned then. However, the two of them cannot handle railway construction work of all provinces. So for now, we have to resort to outsiders in many occasions. ${ }^{10}$ Technical talent is scarce, especially in management. "The already completed railway construction projects in China were mostly managed by foreigners.
10. "On the Development of China's Railway", Diplomatic Review, No.250, 9-08-10. (in Chinese) 
Table 3. The number of new schools and students

\begin{tabular}{|l|l|l|l|l|l|l|}
\hline \multicolumn{1}{|c|}{ Year } & \multicolumn{1}{c|}{1895} & \multicolumn{1}{c|}{1896} & \multicolumn{1}{c|}{1897} & \multicolumn{1}{c|}{1898} & \multicolumn{1}{c|}{1899} & 1902 \\
\hline Number of new schools & 3 & 14 & 17 & 14 & 150 & \\
\hline Number of students & & & & & & 6912 \\
\hline Year & 1907 & 1908 & 1909 & 1912 & 1916 & 1919 \\
\hline Number of new schools & 37888 & 47995 & 1626720 & & & \\
\hline Number of students & 1024988 & 1300739 & & 2933387 & 3974454 & 5704254 \\
\hline
\end{tabular}

With everything depending on foreigners and in their command, we do not know what management is. Some domestic staff in management position is mostly candidates who just served as postmasters or inspectors at best." These persons just take the positions as a springboard for promotion, and usually don't pay much attention to the essential matters of transportation and the duty of management ${ }^{11}$ Although the Sichuan Provincial Railway Company stipulated in its articles of association to hire Chinese engineers in priority, it also expressed that if it wants to hire people whether from Eastern or Western countries, the company should make a proper contract and specify the limits of authority. This shows their doubts in the quality and quantity of Chinese engineers. ${ }^{12}$ The urgent need for talents has become the driving force for the rapid development of new higher learning institutions. In 1905, when the Imperial examination system was abolished by the Qing Government, new schools sprang up all over the country. The number of new schools and students are shown in the "Table 3 " above: ${ }^{13}$

\section{THE DEVELOPMENT OF FOREIGN LANGUAGE EDUCATION IN SICHUAN UNIVERSITIES AFTER THE SICHUAN CHINESE AND WESTERN SCHOOL}

With the reform of academic system and the further development of higher education in Sichuan, Sichuan Chinese and Western School merged with Jinjiang Academy and Zunjing

11. Wuding. Chapter on Railway Management. Youdaily, No. 1 (May 1907). (in Chinese)

12. Implementation Committee of the Chinese Cultural Revival Movement (Ed.). Anthology of Modern and Contemporary History of China. Taipei: Taiwan Commercial Press, 1985.

13. Lin Zhengzhen. The Change of Schooling System in Late Qing Dynasty and the Introduction of Western Educational System. Quarterly Journal of General Education, no.4, 1994. (in Chinese)
Academy in 1902, forming the Sichuan General Provincial School, which was renamed Sichuan Provincial Capital Higher School in the following year, and was renamed Sichuan Higher School after the Revolution of 1911. After that, it went through the tortuous development of National Chengdu Higher Normal School and National Chengdu University, and finally evolved into National Sichuan University in 1931 through the merger of the three schools, which is now Sichuan University. [2] Although the school has gone through many changes, the purpose of spreading advanced science and technology and culture inherited from the Sichuan Chinese and Western School has not changed. The development of foreign language education and other advanced science and technology professional education has opened a "window to the world" for inland Sichuan. During this period, Sichuan higher foreign language education has showed not only its importance as a basic subject, but also its specialized development direction, just as the Sichuan Chinese and Western School. Since then, all universities have taken foreign language courses as an important basic subject. Sichuan Provincial Capital Higher School (later renamed Sichuan Institute of Higher Learning) "takes the study of Confucian classics as the base, to set up right values for students, thus impart the Western studies to them and train their abilities, in the hope that they will become useful persons, even versatile ones to serve the country and put an end to the country's ills." ${ }^{14}$ [5] Foreign languages (including Optional English, German and Japanese, and Latin for medical studies) are among the most important courses in the public curriculum of the Department of Formal Studies, along with Confucian classics. In terms of teaching method, the advanced Nesfield Grammar was adopted. "Table 4" shows the curriculum schedule of Mr. Guo Moruo, who studied in Class 9, Second

14. Shu Xincheng. Data on the History of Modern Chinese Education. People's Education Press, 1961. (in Chinese) 
Department of Formal Studies in Science, Sichuan Institute of Higher Learning in 1912: ${ }^{15}$ [1]

From Mr. Guo's curriculum schedule shown in "Table 4", it can be seen that the advanced configuration of the school's curriculum system. With "Western languages and Western skills" as the main content, the goal was to cultivate useful people who can effectively serve the society. Foreign language courses, as the foundation of Western learning, also occupied an important position. There were as many as 11 class hours in a week, and they had surpassed the traditional subjects and ranked first among all subjects. The railway school attached to the school also taught all subjects in English, which seems to be a very high requirement for foreign language teaching.

After Sichuan Institute of Higher Learning, the school has experienced several development periods of National Chengdu Higher Normal School, National Chengdu University and National Chengdu Normal University, as well as the National Sichuan University after the merger of the three schools. Despite the twists and turns in the development of schools, they all set up special foreign language departments or foreign language departments. In the curriculum, foreign language (mainly English) was regarded as an important basic course for students, and great importance was attached to foreign language teaching. For example, in 1918, the English Department was listed as a single department in the curriculum of Chengdu Higher Normal School, with the main course of English and English studies (speaking and reading, composition, grammar, conversation), Chinese and Chinese Literature (speaking and reading, composition, and history of literature), History (Western histories), Philosophy (Introduction to Philosophy), Aesthetics (Outline of Aesthetics), Linguistics, French. All departments are required to make English a common required course for undergraduates and a second foreign language one of the compulsory subjects in all departments except the department of Chinese. In terms of teachers, The English department of National Chengdu Normal University employs Lu Guantai to teach Western History, Zheng Yun to teach English Language Studies, Zhu Guangji to teach English Literature, Tang Shaoyu to teache English composition, $\mathrm{Hu}$ Helen to teach English conversation, Liao Xuezhang and Zhou Guanglu to teach Eanglish, Wu Yingliang and Mao Zuofu to

15. Source: Archives of Sichuan Institute of Higher Learning, Vol. 15. teach Japanese, and over 10 foreign teachers from Japan, UK and US teaching Japanese and English [1]. ${ }^{16}$
16. Source: Archives of National Chengdu Normal University, Vol. 30. 
Table 4. The curriculum schedule of Mr. Guo Moruo

\begin{tabular}{|c|c|c|c|c|c|}
\hline Subjects & Content & Class & Subjects & Content & Class \\
\hline & & hour/week & & & hour/week \\
\hline Chinese & Selections from famous writers 2 & 2 & Ethic & $\begin{array}{l}\text { Song Confucianism } \\
\text { learning case }\end{array}$ & 2 \\
\hline English & Nesfield Grammar & 4 & English & Jiangbo textbook & 4 \\
\hline German & The first textbook & 3 & Physics & Thermology, dynamics & 4 \\
\hline Chemistry & $\begin{array}{l}\text { Compound composed of water } \\
\text { and salt, metal monomer and } \\
\text { element }\end{array}$ & & Algebra & Theorems and equations & 4 \\
\hline $\begin{array}{l}\text { Analytic } \\
\text { Geometry }\end{array}$ & $\begin{array}{l}\text { Application of harmonic column } \\
\text { points and conjugate secant } \\
\text { lines }\end{array}$ & 3 & Triangle & Spherical trigonometry & 2 \\
\hline Calculus & $\begin{array}{l}\text { Successive differentiation and } 3 \\
\text { inference }\end{array}$ & & Gymnastics & Millitary drill & 2 \\
\hline
\end{tabular}

During this period, another important event in the development of higher foreign language education in Sichuan was the establishment of specialized foreign language schools. The Gui-mao School System, promulgated in 1903, established the system of building higher specialized schools and set off a wave of "abolishing imperial examinations and promoting schools" across the country. Accordingly, Sichuan set up five specialized schools, namely Sichuan Politics and Law School, Sichuan General Provincial Agriculture School, Sichuan School of Ancient Learning, Sichuan Industry School and Sichuan Tibetan Language School. The Sichuan Tibetan Language School was renamed Sichuan Official Foreign Language School in 1907, which changed from the original Teaching of Tibetan to foreign languages. In 1912 it was renamed Sichuan Public Foreign Language School and became the first specialized foreign language school. The school had a school system of one-year preparatory courses plus three-year undergraduate courses. Only English and French were available, with grammar, reading, conversation, composition and other courses. Students were also required to take courses in Chinese, linguistics, history, geography, economics, a second foreign language and Esperanto. [2] Ji Shuping and Liao Tianxiang served as the President of the foreign language school successively. Liao Tianxiang supported the new culture movement during his incumbency and was open-minded, and students of the school then were also active in the patriotic student movement during the May Fourth Movement. Although Sichuan Public Foreign Language School was small among the five specialized schools of that time in terms of the number of students (only 95 students and 15 teachers in 1916), this did not prevent the school from producing excellent talents. Mr. Ba Jin was admitted to the school under the name of $\mathrm{Li}$ Yaotang in 1919. He first went to a cram school, then had the preparatory courses, and finally chose the major of French. In 1923, he finished his study and pursued his further education in France. In school, Ba Jin began to learn English, French and Esperanto. In terms of the study of Esperanto, Mr. $\mathrm{Ba} \mathrm{Jin}$ is also regarded as one of the pioneers of The Esperanto movement in China. As for his four years on campus, $\mathrm{Ba}$ Jin once wrote in his memoirs that he read a lot of world classics in school, such as the "David Copperfield" by Charles Dickens, "Treasure Island" by Robert Louis Stevenson, which he liked very much. That kind of narration in the first person also had a great influence on $\mathrm{Ba}$ Jin's literary creation later. ${ }^{17}$

By 1927, five special schools were merged to form the Public Sichuan University, and Public Sichuan Foreign Language School was changed into the School of Foreign Languages of Sichuan Public University. Because there was no post of President in Public Sichuan University, the "University Committee" was formed by the seniors of the five schools to jointly act as the President. Yang Boqian was then the study president of the School of Foreign Languages. [2] This loose system determines that the development of the university will face all kinds of difficulties, but it also makes the discipline construction of it have the characteristics of specialization and depth. Take, for example, a curriculum for students who

17. Ba Jin: Collected Works of Ba Jin, Vol. 10, Sichuan People's Publishing House, 1979. 
graduated from the School of Foreign Languages in August 1929. The student took 34 courses in the four years, 124 credits in total, including (credits in brackets): History of British Literature (6), History of American Literature (3), Selected English Poems (6), Shakespeare's Plays (6), Bernard Shaw's Play (2), History of Greek Literature (3), Greek and Roman Anthology (4), Selections from the Renaissance Period (3), Greco-Roman History (3), Western Histories (6), British History (6), History of the European Wars (3), Selections from the Sketch Book by Washington Irving (3), The Legend of Westfield (2), Collection of Bacon (3), Ruo Shi Lun Wen (3), Yin Shi Lun Wen (3), A Tale of Two Cities (4), Treasure Island (2), Selected Texts of the Middle Ages (3), Selections from Recent Short Stories (4), Classics (3), Rhetoric (2), Chinese Composition (6), English Composition (6), French (4), Latin (2), Greek (6), Political Science (3), Sociology (3), Psychology (3), International Law (3), Education (3) and Ethics (3). ${ }^{18}$ [1] The quantity is so large and they are divided so elaborately that the management even cast modern education into the shade. However, in the turbulent times then, frequent changes of school administration (from 1928 to 1931, there were Yang Boqian, Tan Zhizhen, Yan Di Xun and Song Guangxun among the study presidents), and severe shortage of teaching funds severely restricted the development of the school. In 1930, the School of Foreign Languages had only 25 undergraduates, and the lack of Practical Conversational English and Practical English Courses was also a shortcoming of the schools teaching. In general, although the School of Foreign Languages of Public Sichuan University faced many difficulties in its own development, it has further developed Sichuan higher foreign language education on the basis of inheriting Sichuan Public Foreign Language School, and laid a foundation for foreign language teaching in National Sichuan University after the merger of the three schools.

After the establishment of National Sichuan University, the Department of Foreign Literature was divided into the Department of Literature. At first, Xie Wenbing and Jin Youshi successively served as the department heads. During the period of Acting President Zhang Yi, Zhu Guangqian, a famous educator and translator, was employed as the dean and director of the Department of Foreign Languages. In 1935, the department had 5 19

18. Source: Archives of Public Sichuan University, vol. professors, 12 associate professors and full-time lecturers, and 61 students. [2] The teaching content started from the goal of training senior translators, writers and foreign language teachers, and the curriculum was more practical. The following are the main courses offered by the Foreign Languages Department: Basic English (1) (2), Phonetics, Introduction to Literature, Western History, Bible Stories, Greek and Roman Mythology, History of British Literature, Selected English Short Poems, Selections English Long Poems, British Novels, Advanced Composition, Essays, Biographical Literature, Eighteenth-century English Literature, Nineteenth-century English Literature, British Essay, Modern English and American Prose, Literary Criticism and Second Foreign Language. ${ }^{19}$ [1] Grade one and two mainly carried out basic language training, with attention paid to reading and writing; the third and fourth grades would pay equal attention to the study of literature and language, the selected courses, in addition to literature introduction, literary criticism, etc., focusing more on the study of original works and speeches. At the same time, more attention were paid to students' listening, speaking, writing three basic skills training. Basic English lesson was a special training course. Of the 5 class hours per week, 3 were for direct conversation between teachers, students and students, and 2 for rhetoric and composition. Advanced Composition class focused on English rhetoric and the nature and form of various literary styles, so that students in grade three could write fluent English compositions. In the study of foreign literature, attention was paid to the cultivation of students' ability to criticize and appreciate foreign works. The course of Essays taught various essays such as travel notes, diaries and letters and the forms and properties of various literary styles. It guided students to select and read the above-mentioned works of various genres, and cultivated students' ability to write various literary styles and use English more practically. Textbooks and reference books were used in the course materials, and the teaching was also delivered in English. [3] Great importance was attached to oral practice and practical application. Most of the graduates worked as foreign language teachers in colleges and universities across the country.

\section{CONCLUSION}

19. Source: Archives of National Sichuan University, vol. 5 
From Sichuan Chinese and Western School to the present Sichuan University, the school has gone through all kinds of hardships, but has been inheriting and spreading its culture all the way. Over the past century, it has cultivated state leaders and literary masters such as Zhu De, Ba Jin, Guo Moruo and Yang Shangkun, over 50 academicians of The Chinese Academy of Sciences and the Chinese Academy of Engineering, and countless outstanding talents from all walks of life, making important contributions to the development of Sichuan region and the progress of the whole society. The higher foreign language education of Sichuan, which started from Sichuan Chinese and Western School, has experienced the process of germination, development and improvement together with the development of the school. As the most direct tool to understand foreign countries, foreign language education attracted great attention as the most important new subject in the beginning of new education, which can be seen from the establishment of Sichuan Chinese and Western School. Later, with the further development of modern education, more modern education subjects and contents were introduced into the field of modern higher education, and foreign language education gradually established its status as a basic and instrumental subject of modern education. In the modern history of higher foreign language education in Sichuan, this could be reflected in the further construction and development of foreign language education in colleges and universities in the late Qing Dynasty and the early Republic of China, as well as the establishment of specialized foreign language higher education colleges. In 1931, The National Sichuan University, founded by the confluence of the three universities, was established as a comprehensive institution of higher education in Sichuan since the late Qing Dynasty and the early Republic of China. The department of Foreign Languages was an important instrumental basic subject in the whole university education, which not only had the depth of professional research but also had the benefit of practical education. Since then, the higher foreign language education in Sichuan had taken shape in modern times, with the process of its development and perfection still under way.

To trace back to its origin, the establishment of Sichuan Chinese and Western School was a process of the modernization of higher education in Sichuan, which began with foreign language education. And in this process, foreign language education also went ahead of the modernization of other disciplines. In fact, the modernization of Chinese higher education is the product of national salvation on the cultural level under the situation of national disaster in the late Qing Dynasty. It is the result of the forced transformation of traditional culture under the crisis and the communication and integration with foreign western culture, and the higher foreign language education is the most direct reflection of this communication and integration. The development of higher foreign language education in Sichuan is a epitome of the development of modern higher foreign language education in China. The discussion of this issue is not only beneficial to the study of the development process and problems of modern Chinese higher foreign language education, but also can reveal some laws of the development of modern Chinese higher foreign language education to some extent. Here, this paper only serves as an initiator of this topic and the author embraces corrections and any other brilliant ideas.

\section{AUTHORS' CONTRIBUTIONS}

This article is independently completed by Luhua Gan.

\section{REFERENCES}

[1] Archives of Sichuan University: "Archives of Sichuan Chinese and Western School", "Archives of Sichuan Institute of Higher Learning", "Archives of Sichuan General Normal School", "Archives of Chengdu Higher Normal School", "Archives of National Chengdu University", "Archives of Public Sichuan University", "Archives of National Chengdu Normal University" and "Archives of National Sichuan University". (in Chinese)

[2] The editorial board of "Historical Records of Sichuan University". "Historical Records of Sichuan University". Sichuan University Press, 2006. (in Chinese)

[3] Dang Yuewu. "Memory of Sichuan University - A Selection of School History and Culture, Vol. 1". (in Chinese)

[4] Dang Yuewu. "Memory of Sichuan University - A Selection of School History and Culture, Vol. 1: Lu Chuanlin and Sichuan University", Sichuan University Press, 2011. (in Chinese) 
[5] Shu Xincheng. Data on the History of Modern Chinese Education. People's Education Press, 1961. (in Chinese)

[6] Zhu Youhuan. Historical Materials of Modern Chinese Academic System. Shanghai: East China Normal University Press, 1987. (in Chinese)

[7] Implementation Committee of the Chinese Cultural Revival Movement (Ed.). Anthology of Modern and Contemporary History of China. Taipei: Taiwan Commercial Press, 1985. (in Chinese)

[8] Other publications before the founding of the People's Republic of China include Shendaily, Youdaily, National Sichuan University Weekly, etc. (in Chinese) 